\title{
Insufficient Radiofrequency Ablation Treated Hepatocellular Carcinoma Cells Promote Metastasis by Up-Regulation ITGB3
}

\author{
Ning Zhang ${ }^{1 *}$, Dening Ma2*, Lu Wang ${ }^{1 *}$, Xiaodong Zhu³, Qi Pan ${ }^{1}$, Yiming Zhao ${ }^{1}$, Weiping Zhu1, Jiamin \\ Zhou ${ }^{1}$, Longrong Wang ${ }^{1}$, Zongtao Chai ${ }^{4}$, Jianyang Ao ${ }^{5}$, Huichuan Sun ${ }^{3}$, Zhaoyou Tang ${ }^{3 凶}$ \\ 1. Department of Liver Surgery, Fudan University Shanghai Cancer Center, Cancer Hospital, Shanghai, China; \\ 2. Department of Colorectal Cancer Surgery, Zhejiang Cancer Hospital, Hangzhou, Zhejiang, China; \\ 3. Liver Cancer Institute, Zhongshan Hospital, Fudan University; Key Laboratory of Carcinogenesis and Cancer Invasion (Fudan University), Ministry of \\ Education, Shanghai, China; \\ 4. Department of Hepatic Surgery VI, Eastern Hepatobiliary Surgery Hospital, Second Military Medical University, Shanghai, China; \\ 5. Department of Hepatobiliary Surgery, the First Affiliated Hospital of Wenzhou Medical University, Wenzhou, Zhejiang, China. \\ * These authors contributed equally to this work.
}

$\triangle$ Corresponding author: Zhaoyou Tang, MD, Professor of Surgery, Address: Liver Cancer Institute and Zhongshan Hospital, Fudan University. 180 Feng Lin Road, Shanghai, 200032, P. R. China Tel \& Fax: +86-21-64037181 E-mail: tang.zhaoyou@zs-hospital.sh.cn

(C) Ivyspring International Publisher. This is an open access article distributed under the terms of the Creative Commons Attribution (CC BY-NC) license (https://creativecommons.org/licenses/by-nc/4.0/). See http://ivyspring.com/terms for full terms and conditions.

Received: 2017.05.01; Accepted: 2017.08.16; Published: 2017.10.17

\begin{abstract}
Radiofrequency ablation (RFA) is one of the standards of care for early stage hepatocellular carcinoma (HCC). However, rapid progression of residual tumor after RFA has been confirmed. The aim of this study was to investigate the underlying mechanism of this phenomenon. Human HCC cell lines HCCLM3 and HepG2 were employed to establish insufficient RFA models in vivo and in vitro, respectively. The effects of insufficient RFA on metastatic potential of residual tumors were evaluated. The molecular changes after insufficient RFA were evaluated by PCR array, western blot, immunofluorescence, and immunohistochemistry. Results showed that insufficient RFA significantly promoted lung and intrahepatic residual tumor cells in vivo, and heat intervention promoted migration and invasion of hepatoma cells in vitro. PCR array revealed that the expression of integrin $\beta 3$ (ITGB3) and MMP2 were up-regulated in the residual tumors of HCCLM3 xenograft model. The up-regulation of ITGB3 was confirmed by qRT-PCR, Western blot and immunohistochemistry. Knockdown ITGB3 expression in HCCLM3 cells by shRNA significantly lowered the pro-metastatic effects of insufficient RFA. Mechanism studies indicated that ITGB3 mediated the expression of MMP2 by activing FAK/PI3K/AKT signaling pathway. The up-regulation of ITGB3 contributed to enhanced metastatic potential of residual cancer in HCCLM3 model after insufficient RFA. Targeting ITGB3 expression may further improve the clinical effects of RFA.
\end{abstract}

Key words: Radiofrequency ablation (RFA); Hepatocellular carcinoma (HCC); ITGB3; Metastasis.

\section{Introduction}

Hepatocellular carcinoma (HCC) is one of the most common human cancers worldwide, particularly in East and South-East Asia [1]. Although surgical resection and liver transplantation are the two main modalities of radical treatment for HCC, the application of these treatments are limited owing to the severe liver dysfunction and the shortage of liver grafts [2]. Under these circumstances, several non-surgical techniques have been introduced for treatment of HCC. Radiofrequency ablation (RFA) is one of the local treatment modalities competes with surgery for $\mathrm{HCC}<3 \mathrm{~cm}$ and is currently widely used owing to its simple, safety, minimal invasiveness, repeatability and shorter hospitalization $[3,4]$.

However, the complete tumor ablation rate with RFA is less satisfied. Local tumor recurrence rates 
range from 3.2-26\% [5-7]. Although the rapid progression of residual HCC after insufficient ablation were reported on the rise $[8,9]$, the underlying mechanisms behind this phenomenon are still less understood.

Tumor metastasis is considered to be a multi-step process characterized by a high degree of complexity. More specifically, the metastatic cascade consists of several steps, including detachment of tumor cells from the primary site, invasion of the extracellular matrix (ECM), intravasation into the blood stream, dissemination through the circulation, extravasation into the target organs and formation of the secondary site [10]. Cell adhesion molecules such as integrin, cadherin, and immunoglobulin superfamilies have been studied extensively in the context of tumor progression and metastasis. Because integrins that express on the surface of a cell determine whether the cell can adhere to and survive in a particular microenvironment, the matching of integrins and ligands play a key role in tumor metastasis [11]. Integrins are a family of transmembrane glycoprotein adhesion receptors that play central roles in the biology of metazoan by controlling cell adhesion, migration, differentiation, and apoptosis. Integrins consist of $\alpha$ and $\beta$ subunits, which connect adhesive proteins in the ECM to the intracellular actin cytoskeleton, there are at least 19 a-subunits and $8 \beta$-subunits that can associate to form 25 unique integrin heterodimers [12-15]. $\beta 3$ integrin gene has 15 exons and covering an area of $60 \mathrm{~kb}$ located on chromosome 17q21.3 [16,17]. There are two members in the $\beta 3$ integrin family, aIIb $\beta 3$ and av $\beta 3$. aIIb $\beta 3$ is a receptor expressed mainly on the surface of platelets and their precursors - megakaryocytes, and this integrin plays a pivotal role in platelet aggregation and thrombus formation. Whereas, av $\beta 3$ is expressed on the surface of endothelial cells, smooth muscle cells, monocytes, and platelets [18]. The expression of $\beta 3$ integrin is mostly associated with the ability of tumor metastasis and had been reported to enhance the metastatic potential of breast cancer, prostate cancer and murine melanoma [19-21]. However, the studies of correlation between $\beta 3$ integrin and the metastasis of HCC were few.

The present study analyses the relationship between insufficient RFA and metastatic potential of residual HCC, and the related underlying molecular mechanism. Our findings reveal that integrin $\beta 3$ probably play a crucial role in the changes of metastasis potential of residual cancer.

\section{Materials and Methods}

The experiments were approved by the Ethic Committee of Zhongshan Hospital, Fudan University, per-formed in accordance with the approved guidelines, and informed consent was obtained from all subjects.

\section{Animal model and cell lines}

Male athymic BALB/c nu/nu mice, weighing 18-20g at 4-6 weeks of age, were obtained from SLAC Laboratory Animal Co, Ltd, Shanghai, China. All mice were maintained under specific pathogen free conditions. All animal protocols were approved by the Ethical Committee on Animal Experiments of Animal Care Committee of Fudan University, Shanghai, China.

Two HCC cell lines were used: HepG2 cells (human HCC cell line with low metastatic potential) and HCCLM3 cells (human HCC cell lines with high metastatic potential), which were established in author's institution. The stable green fluorescent protein-expressing HepG2-G and HCCLM3-G cell lines, derived from HepG2 and HCCLM3 cells, respectively, were used for in vivo experiments [22]. The cells were maintained in Dulbecco's modified Eagle's medium (DMEM, Gibco BRL, Rockville, MD, United States) with 10\% fetal bovine serum (Life Technologies, Carlsbad, CA, United States), 100 $\mathrm{mg} / \mathrm{mL}$ penicillin $\mathrm{G}$ at $37{ }^{\circ} \mathrm{C}$ in a humidified atmosphere containing $5 \% \mathrm{CO}_{2}$.

\section{Establishment of incomplete RFA orthotopic nude mouse model}

The human HCC orthotopic nude mouse models with HCCLM3-G cells and HepG2-G cells were established as previously described [23]. The nude mice were randomly divided into insufficient RFA group $(n=16)$ and a sham-operated group as the control group $(n=16)$. Two weeks after orthotopic implantation, the insufficient RFA operation was as follows: insufficient RFA mice underwent laparotomy with exposure of transplantation tumor, considering the weight and volume of nude mice, RFA was performed in a lower energy protocol, in which the out power was $5 \mathrm{w}$ and the duration was about 30 seconds, in order to keep the existence of residual cancer. The mice of control group were sham-operated by inserting a needle electrode into tumor without performing ablation.

\section{Parameters observed}

To evaluate the effects of insufficient RFA on tumor growth, intrahepatic and distant metastasis, five weeks after orthotopic implantation, 6 nude mice from each group were randomly sacrificed to examine tumor growth, intrahepatic and distant metastasis. The largest (a) and smallest (b) tumor diameters were measured with vernier caliper, and the tumor volume was calculated as follows: Tumor volume $\left(\mathrm{mm}^{3}\right)=\mathrm{a}$ 
$(\mathrm{mm}) \times \mathrm{b}(\mathrm{mm}) \times \mathrm{b}(\mathrm{mm}) / 2$ [24]. The intrahepatic and lung metastasis, and peritoneal seeding of HCCLM3-G or HepG2-G cells was visualized using fluorescence stereomicroscopy (Leica, Wetzlar, Germany). The lung tissues were sectioned serially and hematoxylin-eosin (H\&E) staining to confirmed the results above.

\section{PCR array}

Three tumor tissue that came from insufficient RFA group and the control group were pooled to extract total RNA and studied using the tumor metastasis PCR Array (PAHS-028Z) according to the manufacturer's instructions.

\section{Re-inoculation experiment}

To further studying the effects of insufficient RFA on metastasis and invasiveness potential of HCC, we conducted a re-inoculation experiment. On day 7 after insufficient RFA and sham-operation, one mouse from each group was sacrificed to serve as xenografts. Tumor fragments of equal volume $\left(2 \times 2 \times 2 \mathrm{~mm}^{3}\right)$ from each mouse of the insufficient RFA group and sham-operation group were reinoculated into the livers of each new recipient mice correspondently. These mice, divided into control (bearing sham-operation treated tumors, $\mathrm{n}=16$ ) and trial (bearing insufficient RFA treated tumors, $\mathrm{n}=16$ ) group, were then kept under standard conditions without any intervention. 6 weeks after re-inoculation, six randomly selected mice from each group were sacrificed, and metastasis related parameters including tumor growth, intrahepatic and lung metastasis, and peritoneal seeding were assessed. Tumor tissues from re-inoculated mice were also prepared for histological study. The remaining mice from each group were kept for survival analysis.

\section{Heat treatment in vitro}

HCC cells were seeded into the 6 -well plates $(5 \times$ $10^{4}$ cells/well). After $24 \mathrm{~h}$, the plates were sealed with parafilm and submerged in a water bath set to the target temperature for $10 \mathrm{~min}$. The target temperature of $39^{\circ} \mathrm{C}, 42^{\circ} \mathrm{C}, 45^{\circ} \mathrm{C}$ for $\mathrm{HCCLM} 3$ cells and $41^{\circ} \mathrm{C}, 44^{\circ} \mathrm{C}$, $47^{\circ} \mathrm{C}$ for HepG2 cells, which were designed to simulate the effects of insufficient RFA and $37^{\circ} \mathrm{C}$ for $10 \mathrm{~min}$ as the control treatment.

\section{Cell migration, invasion assay}

The cell migration ability was assessed by transwell assay (Corning, NY). Briefly, $8 \times 10^{4}$ cells in serum-free DMEM were seeded into the upper chamber of each well of 24-well plates containing $8.0-\mu \mathrm{m}$ pore size membranes. DMEM containing $10 \%$ fetal bovine serum (FBS) was added to the lower chamber of each well. After $24 \mathrm{~h}$, the cell that did not migrate were removed from the upper surface of the membranes using a sterile cotton swab and the cell that had reached the underside of the membrane were stained with Giemsa (Sigma), counted at $\times 200$ magnification in five randomly selected areas per well. The cell invasion assay was carried out similarly, except that $80 \mu \mathrm{L}$ Matrigel $(0.8 \mathrm{mg} / \mathrm{mL}, \quad B D$ Biosciences) was added to each well $6 \mathrm{~h}$ before cells were seeded on the membrane, the results were examined after $48 \mathrm{~h}$.

\section{Cell transfection}

pGCSIL-GFP-shITGB3 and pGC-FU-GFP-ITGB3 lentiviral vectors were purchased from Shanghai GeneChem Co. pGC-FU-GFP-ITGB3 was transfected into HCCLM3 cells with overexpression of ITGB3 and pGCSIL-GFP-shITGB3 was transfected into HCCLM3 cells with lower expression of ITGB3. pGCSIL-GFP and pGC-FU-GFP lentiviral vectors were used as controls.

\section{Quantitative Real-time PCR Analysis}

PCR procedures are described elsewhere [25]. The following primers for amplification of human genes were used: ITGB3 forward primer 5'CCTTCACCAATATCACGTACCG-3' and reverse primer 5'-CTCCCCACAAATACTGTCCTC-3'; MMP2 forward primer $5^{\prime}$-AAGTGGGACAAGAACCAGAT C-3' and reverse primer 5'- GATTCGAGAAAA CCGCAGTG-3'.

\section{Western Blot Analysis}

The western blot procedures used are described elsewhere [26]. Primary antibodies used including: anti-ITGB3, anti-MMP2 (Abcam, Cambridge, MA), anti-FAK, anti-p-FAK, anti-AKT, anti-p-AKT (Epitomics, Burlingame, CA) and anti- $\beta$-actin (Boster, Wuhan, China).

\section{Immunofluorescence and Immunohistochemistry}

These two assays were carried out as described before [27]. Primary antibodies used including: anti-ITGB3, anti-MMP2 (Abcam, Cambridge, MA).

\section{Statistical analysis}

Statistical comparisons were performed using the Student's $t$ test when data were normally distributed or using the nonparametric analyses of chi-square test when data were not normally distributed. The Kaplan-Meier method with log-rank test was used for survival analysis. Significance was defined as $P<0.05$. Calculations were made using SPSS 20.0 (SPSS Inc. Chicago, IL, USA). 


\section{Results}

\section{Insufficient RFA promoted invasiveness and distant metastasis in orthotopic nude mouse model}

In HCCLM3-G xenografts, bioluminescence showed the higher incidence rate of lung metastasis $(6 / 6$ vs. $1 / 6, P=0.004$, Fig. $1 \mathrm{~A}, \mathrm{~B})$ and intrahepatic metastasis (5/6 vs. $0 / 6, P=0.015$, Fig. $1 C, D)$ in insufficient RFA group than that in sham-operated mice. Analysis of serial paraffin sections of lung and liver xenograft also identified the above results (Fig.
1B), the mean numbers of lung metastases in each groups were $26.33 \pm 1.84$ vs. $3.50 \pm 3.50$ (insufficient RFA vs. control, $P<0.001)$. In contrast, insufficient RFA could not lead to intrahepatic dissemination and lung metastasis in HepG2-G model, but increased intraperitoneal seeding that detected by bioluminescence (Fig. 1E), in view of the low metastatic potential of HepG2 cells, this phenomenon might provide the convincing evidence to support the pro-metastatic effects of insufficient RFA to a certain extant in HepG2-G xenograft.
A

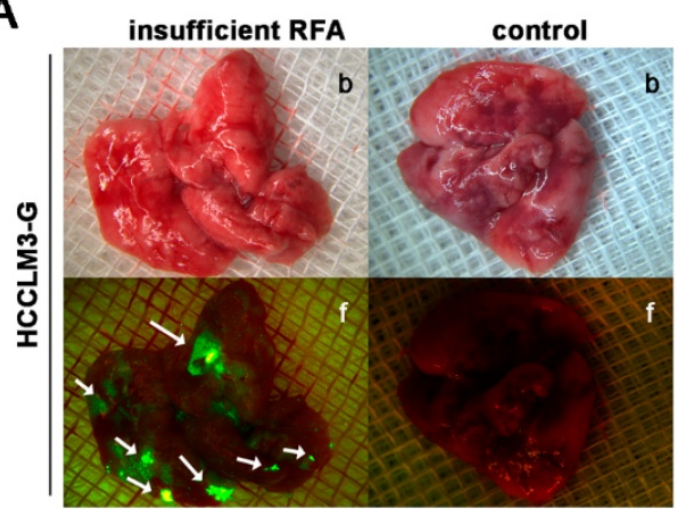

C

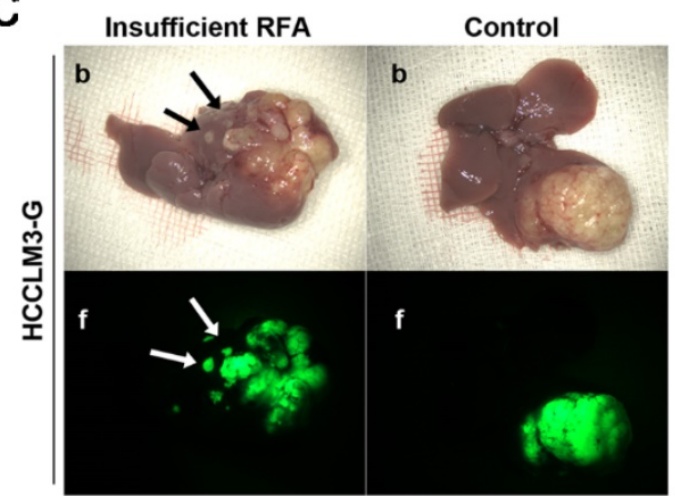

E

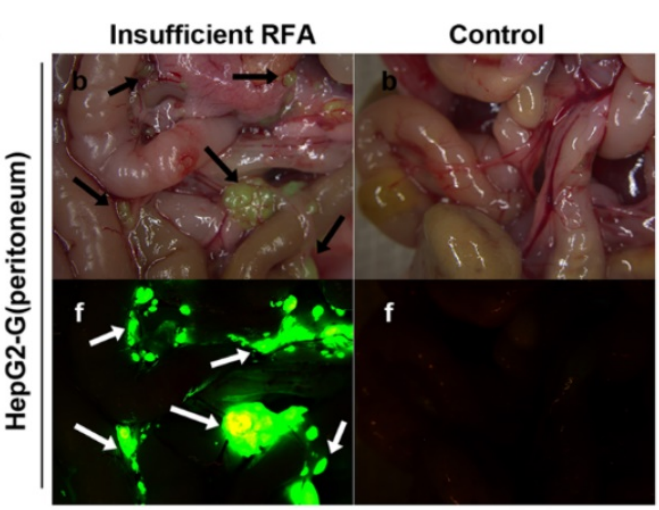

B
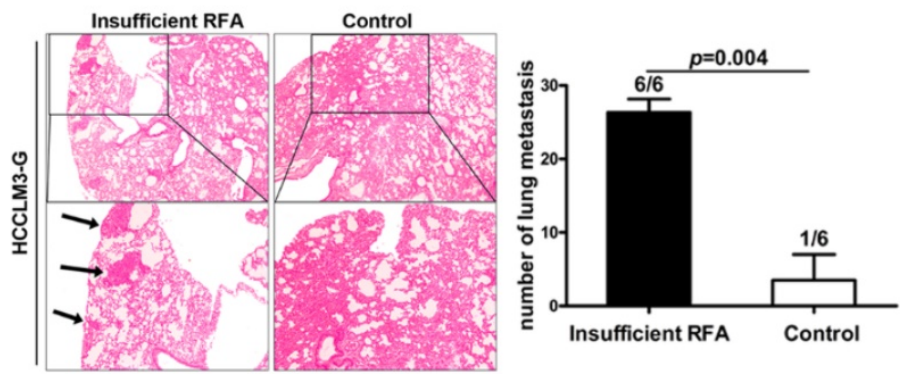

D

Insufficient RFA
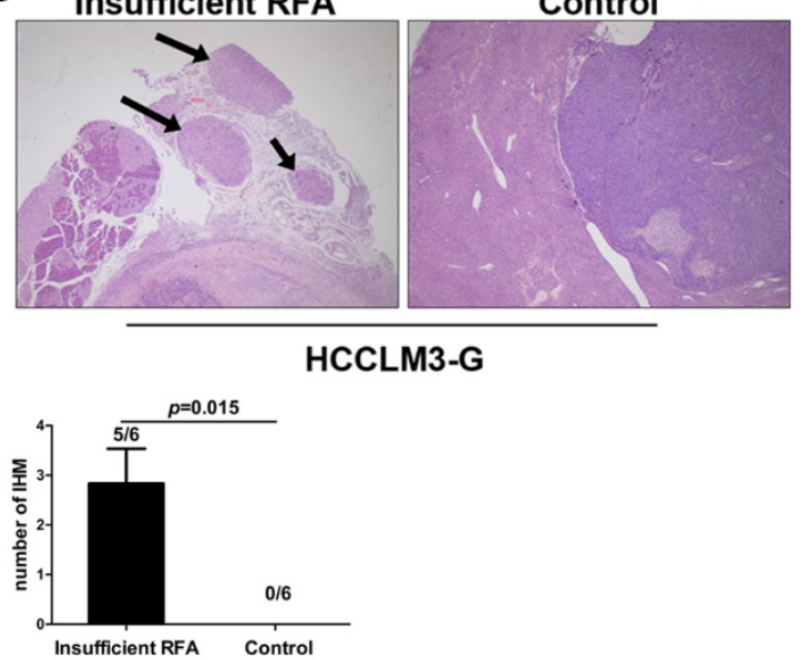

Figure 1. Insufficient RFA enhanced invasiveness and metastatic potential in HCCLM3-G and HepG2-G orthotopic HCC models. A Insufficient RFA enhanced the incidence of lung metastasis in HCCLM3-G model $(6 / 6$ vs $1 / 6, P=0.003)$, compared with the control by both bright field (b) and fluorescence ( $f$ ) (white arrows indicate lung metastases). B Hematoxylin-eosin staining also showed more lung metastasis in insufficient RFA group (black arrows indicate lung metastases) ( $26.33 \pm 1.84$ versus $3.50 \pm 3.50$, $P<0.001)$. C Insufficient RFA induced intrahepatic metastasis (IHM) in HCCLM3-G model $(5 / 6$ vs $0 / 6, P=0.003)$, the tumor from control group was compared with insufficient RFA treated tumor by both bright field (b) and fluorescence (f) (arrows indicate IHM). D Hematoxylin-eosin staining confirmed that insufficient RFA induced more IHM, the number of IHM was greater in the insufficient RFA group compared to the control group (black arrows indicate IHM) ( $2.83 \pm 0.70$ vs $0, P=0.01$ ). $E$ Insufficient RFA increased intraperitoneal metastasis in HepG2-G model (arrows indicate intraperitoneal seeding lesions), compared with matched controls (6/6 vs $0 / 6, P=0.001)$. 


\section{Residual tumors after insufficient RFA intervention exhibited intensive invasive and metastatic potential in re-transplantation HCC nude mice model}

To further evaluate the change of metastatic potential of xenograft after insufficient RFA, HCCLM3-G and HepG2-G xenografts from the insufficient RFA group and the matched control group were re-transplanted into the livers of new recipient mice. Five weeks after re-transplantation, tumor sizes in the trial (bearing insufficient RFA pre-treated tumors) and control (bearing tumors derived from pre-control group) groups were 4180.17 $\pm 1394.15 \mathrm{~mm}^{3}$ and $1681.83 \pm 624.33 \mathrm{~mm}^{3}(P=0.005)$ respectively (Fig. 2A). Bioluminescence revealed that insufficient RFA pre-treated tumors gave rise to spontaneous lung metastasis in $100 \%(6 / 6)$ of the mice in the trial group (Fig. 2B). In contrast, lung metastasis was found in only $16.67 \%(1 / 6)$ of the mice in controls. In HepG2-G model, tumor sizes in the insufficient RFA group and the control group were $5140.17 \pm 1207.42 \mathrm{~mm}^{3}$ and $4665.83 \pm 1739.61 \mathrm{~mm}^{3}$ $(P=0.595)$, respectively (Fig. 2A). Meanwhile, lung metastasis, IHM and peritoneal seeding were also not observed in both two groups (Fig. 2C). The mean survival time of the HCCLM3-G bearing mice in trail group was significantly less than that in control (61.67 \pm 1.09 day vs. $69.00 \pm 1.18$ day, $P=0.01$ ), and the similar trend of mean survival time in HepG2 models was not observed $(71.33 \pm 1.09$ day vs. $71.67 \pm 1.23$ day, $P=0.526$ ) (Fig. 2D).

\section{Insufficient RFA promoted migration and invasion of HCC cell in vitro}

In the migration assay (Fig. 3A), the HCCLM3 cells were checked at $24 \mathrm{~h}$ after the heat intervention of $39^{\circ} \mathrm{C}, 42^{\circ} \mathrm{C}, 45^{\circ} \mathrm{C}$ for $10 \mathrm{~min}$, the number of cells through the membrane were $21.60 \pm 1.99,46.60 \pm 4.02$, $81.00 \pm 5.10$, respectively, which were significantly more than that in control $(10.20 \pm 1.16)$, for the HepG2 cells, the heated cells demonstrated the higher migration ability, the cells were examined at $24 \mathrm{~h}$ after the heat intervention of $41^{\circ} \mathrm{C}, 44^{\circ} \mathrm{C}, 47^{\circ} \mathrm{C}$ for $10 \mathrm{~min}$, the number of cells through the membrane were 22.00 $\pm 2.79,36.00 \pm 2.10,58.80 \pm 3.32$, respectively, the number in control was $5.20 \pm 1.43$. On the other hand, the same trend was observed in the invasion assay (Fig. 3B), heat intervention could significantly increase the invasiveness of HCCLM3 cells and HepG2 cells.

Insufficient RFA could up-regulated expression of the metastasis related genes Integrin $\beta 3$ (ITGB3) and MMP2 in vivo and in vitro

Owing to the significant enhancement effect of invasiveness was observed in HCCLM3-GFP model, tumor tissue from this model was chosen to be checked by PCR array. The testing results showed that 3 metastasis-related genes (ITGB3, TIMP3, MMP2) were significantly up-regulated by more than 1.5 -fold in insufficient RFA HCCLM3-G xenografts, compared with the controls (Fig. 4A). Up-regulation of ITGB3 and MMP2 by insufficient RFA were confirmed by Western blot (Fig. 4B). Moreover, the similar trend was verified by immunohistochemistry staining in HCCLM3-GFP xenografts (Fig. 4C). On the other hand, the significant difference of MMP2 expression was observed in HepG2-GFP xenografts, but not in ITGB3 (Fig. 4B, C). Consistent with the in vivo results, western blot (Fig. 4D) and immunofluorescence staining (Fig. 4E) demonstrated the up-regulation of ITGB3 and MMP2 in protein level compared with the control cells, meanwhile, RT-PCR confirmed the above findings in mRNA level (Fig. 4F). However, the same trend in HepG2 cells was only detected in MMP2 expression, not in ITGB3 (Fig. 4D, E, F).

\section{FAK/PI3K/AKT/MMP2 pathway plays a vital role in the change of metastatic potential of residual cancer after insufficient RFA in HCCLM3 cell}

FAK (Focal adhesion kinase) which is a non-receptor tyrosine kinase predominantly localized in focal adhesions of adherent cells has been shown to regulate integrin-mediated signal transduction [28]. Phosphorylation of FAK at tyrosine 397 has been used as a marker of FAK activity. FAK phosphorylation increased in response to heat intervention in HCCLM3 cells. Meanwhile, similar observations were noted in its downstream signaling, including phosphorylation of AKT (Fig. 5A). To verify the initiation role of ITGB3 in this process, the HCC cell lines HCCLM3-LV-shITGB3 with low expression of ITGB3 and the HCCLM3-LV-ITGB3 with high expression of ITGB3 were employed. Western blot analysis showed that the expression of phosphorylation of FAK and AKT were decreased in the heat-treated HCCLM3-LV-shITGB3 cells compared with the wild type HCCLM3 (HCCLM3-WT) cells, moreover, the expression of MMP2 was also not up-regulated. In contrast, the up-regulated phosphorylation level of FAK and AKT were detected in the heated HCCLM3-LV-ITGB3 cells. These observations suggested that up-regulated expression of ITGB3 might activate the FAK/PI3K/AKT signaling pathway and influence the expression of MMP2 (Fig. 5B). To determine whether up-regulated expression of MMP2 was mediated by FAK/PI3K/AKT pathway, employed PI3K/AKT inhibitor LY294002 (Sigma, USA) and FAK inhibitor 
PF573228 (Santa Cruz, USA) to treat the HCCLM3 cells before heat intervention. Western blot analysis showed that the up-regulation of phosphorylation of AKT protein levels induced by activated FAK was inhibited by FAK inhibitor PF573228 (Fig. 5C), in addition, the increased expression of MMP2 in heated
HCCLM3 cells was also inhibited by PI3K/AKT pathway inhibitor LY294002 (Fig. 5D). Taken together, these data suggested that ITGB3 might regulate the expression of MMP2 via activated FAK/PI3K/AKT signaling pathway in the heat-treated HCCLM3 cells.
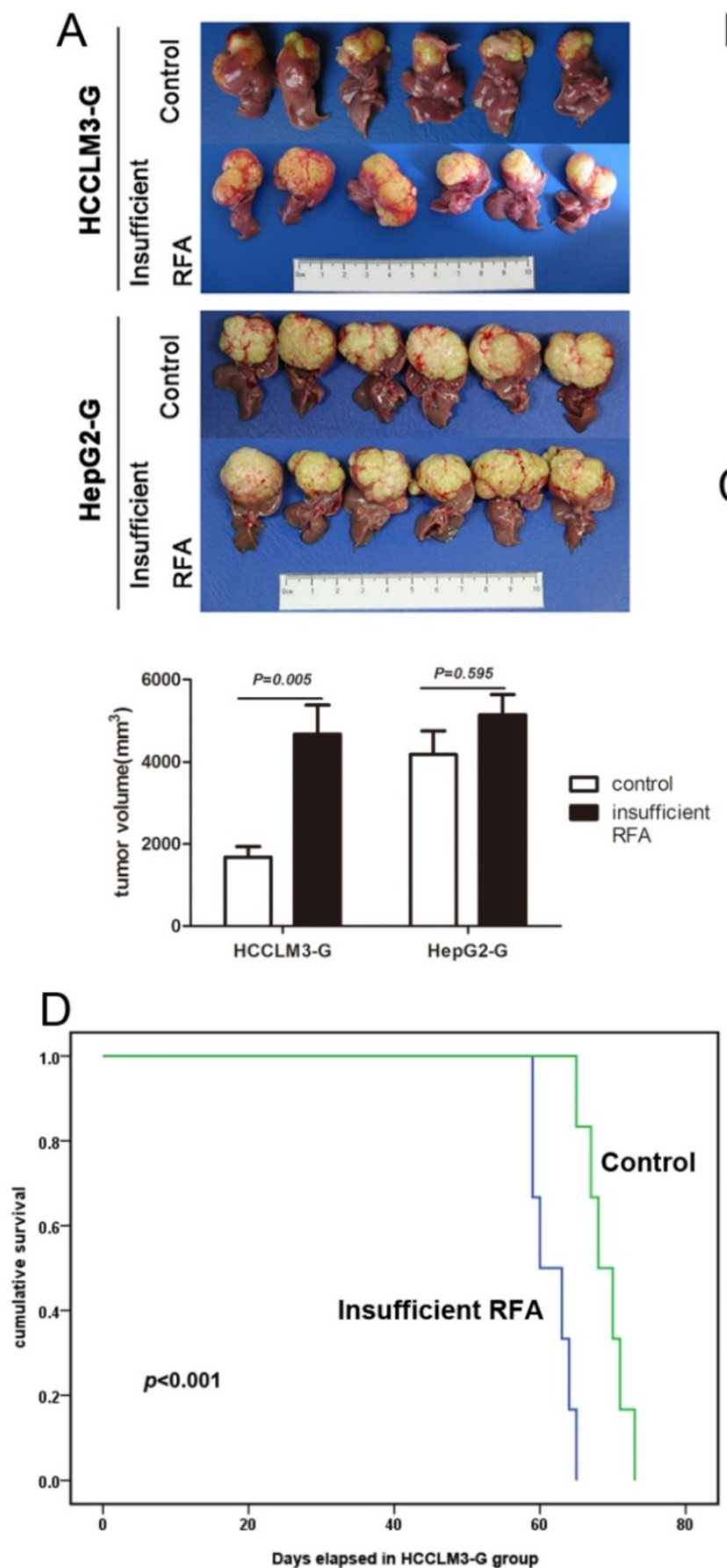
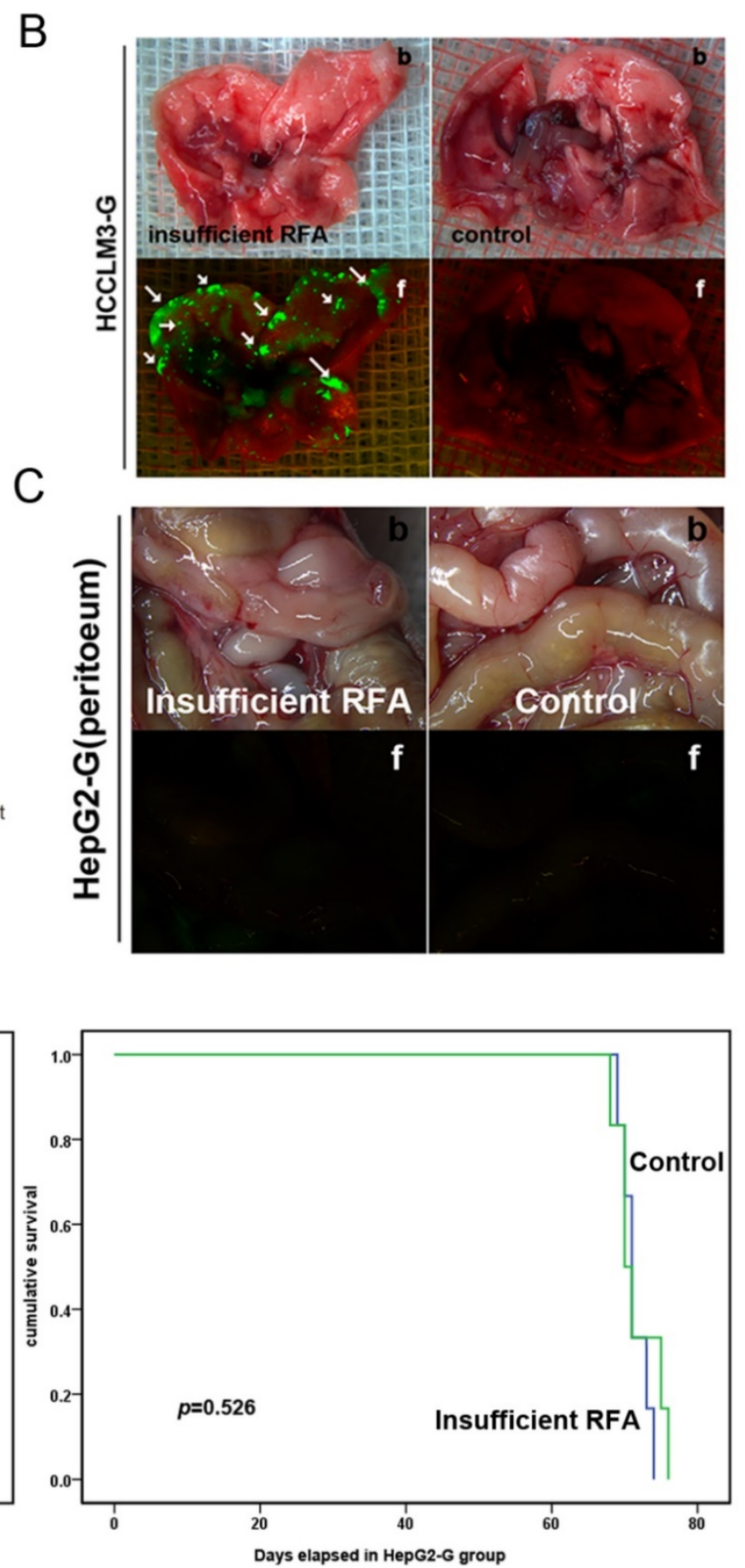

Figure 2. Residual tumors after insufficient RFA intervention exhibited intensive invasive and metastatic potential in re-transplantation HCC nude mice model. A In re-transplantation HCCLM3-G model, the tumor sizes in residual cancer group were greater than those in control $\left(4180.17 \pm 1394.15 \mathrm{~mm}^{3}\right.$ and $\left.1681.83 \pm 624.33 \mathrm{~mm}^{3}, P=0.005\right)$, but not in re-transplantation HepG2-G model $\left(5140.17 \pm 1207.42 \mathrm{~mm}^{3}\right.$ and $\left.4665.83 \pm 1739.61 \mathrm{~mm}^{3}, P=0.595\right)$. B Quantification of bioluminescence showed that insufficient RFA accelerated lung metastasis in re-transplantation HCCLM3-G model, compared with the matched controls (arrows indicate lung metastases), b: bright field, f: fluorescence. $\mathbf{C}$ Intraperitoneal metastasis was not observed in both group of re-transplantation HepG2-G model. D In re-transplantation HCCLM3-G model, the survival times in residual cancer group were less than those in control $(61.67 \pm 1.09$ day vs. 69.00 \pm 1.18 day, $P=0.01)$, in re-transplantation HepG2-G model, there was no significant difference between two groups in survival times $(71.33 \pm 1.09$ day vs. $71.67 \pm 1.23$ day, $P=0.526)$. 

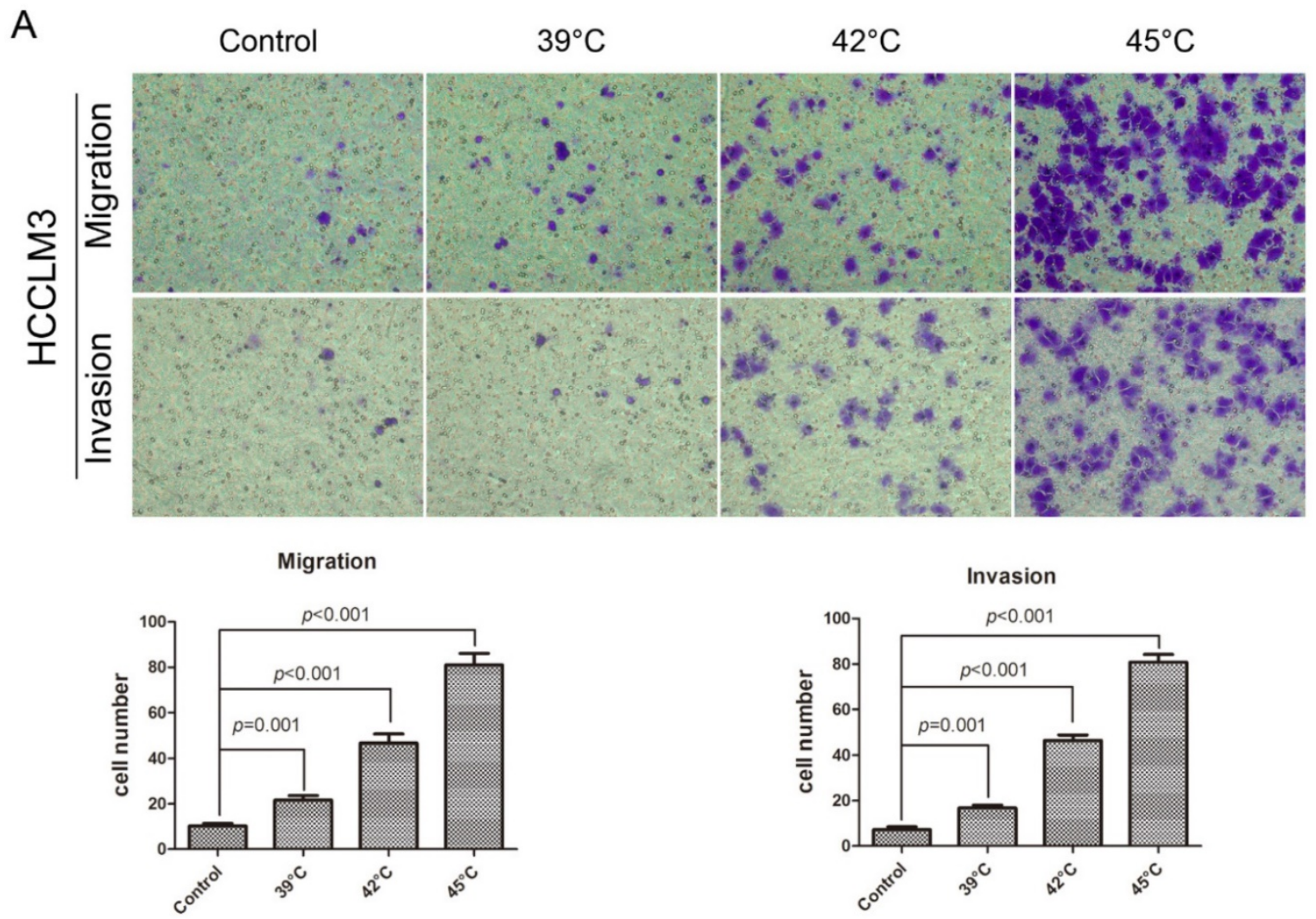

B

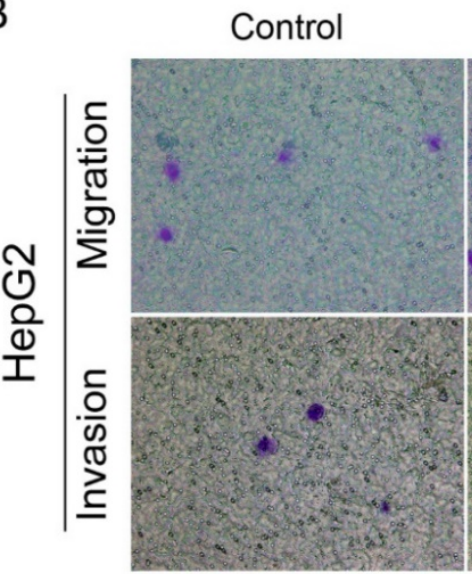

$41^{\circ} \mathrm{C}$

$44^{\circ} \mathrm{C}$

$47^{\circ} \mathrm{C}$

Invasion

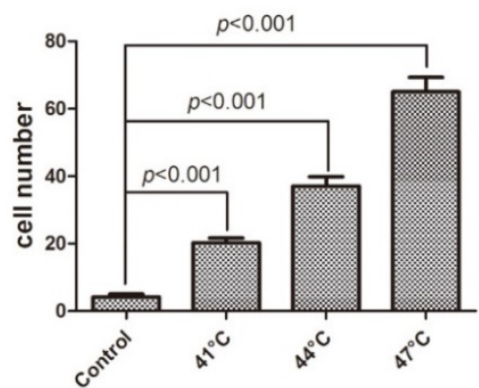

Migration

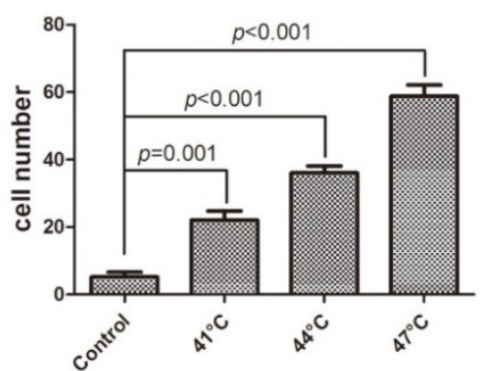

Figure 3. Insufficient RFA promoted migration and invasion of HCC cell in vitro. A In the migration assay, the heated $\mathrm{HCC}$ cells showed the enhanced migration ability compared with the control cells, the HCCLM3 cell were checked at $24 \mathrm{~h}$ after heat intervention of $39^{\circ} \mathrm{C}, 42^{\circ} \mathrm{C}, 45^{\circ} \mathrm{C}$ for $10 \mathrm{~min}$, the number of cells through the membrane were $21.60 \pm 1.99,46.60 \pm 4.02,81.00 \pm 5.10$, respectively, and the number in control was $10.20 \pm 1.16$. And the HepG2 cells was also checked at $24 \mathrm{~h}$ after heat intervention of $41^{\circ} \mathrm{C}, 44^{\circ} \mathrm{C}, 47^{\circ} \mathrm{C}$ for $10 \mathrm{~min}$, the cells which migrated through the membrane were significantly more than those in control $(22.00 \pm 2.79,36.00 \pm 2.10,58.80 \pm 3.32$, vs 5.20 $\pm 1.43)$. B In the invasion assay, the $\mathrm{HCC}$ cells were checked at $48 \mathrm{~h}$ after heat intervention, the number of $\mathrm{HCC}$ cells through the membrane were significantly more than those in control (Heated-HCCLM3: $16.80 \pm 1.28,46.40 \pm 2.36,80.80 \pm 3.43$, vs HCCLM3 in control :7.20 \pm 1.36 ; Heated-HepG2: $20.20 \pm 1.46,37.00 \pm 2.83,65.00 \pm 4.28$, vs HepG2 in control: $4.20 \pm 0.86$ ) 


\begin{tabular}{lcc} 
A & & \\
\hline Gene symbol & Fold difference & $P$ value \\
\hline ITGB3 & 3.47 & .0298 \\
TIMP3 & 1.87 & .0200 \\
MMP2 & 1.70 & .0498 \\
\hline
\end{tabular}

B
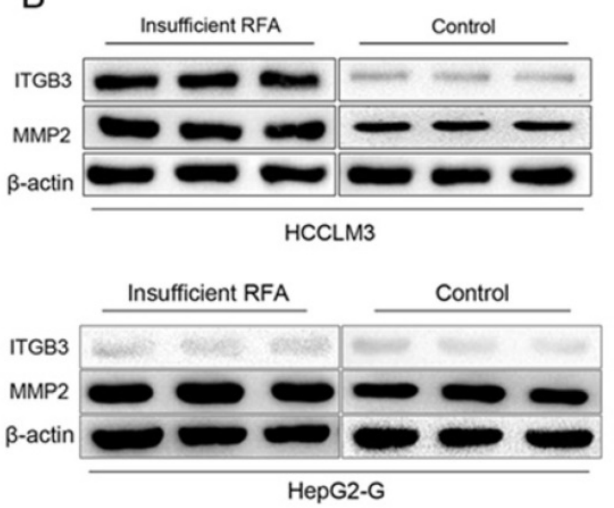

D
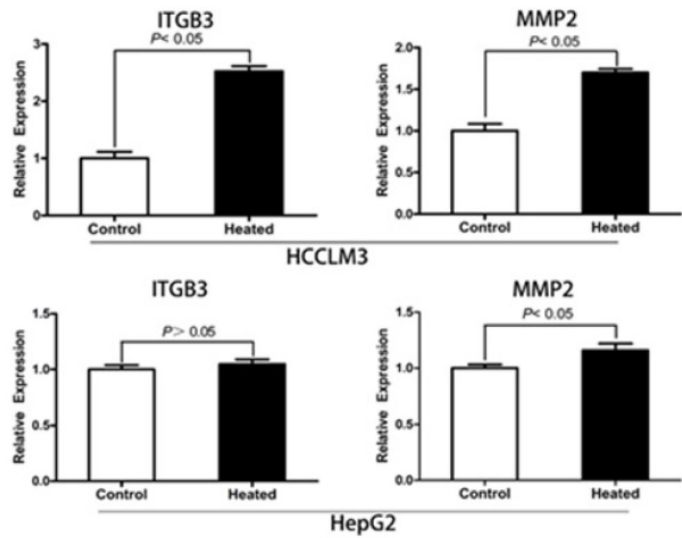

C
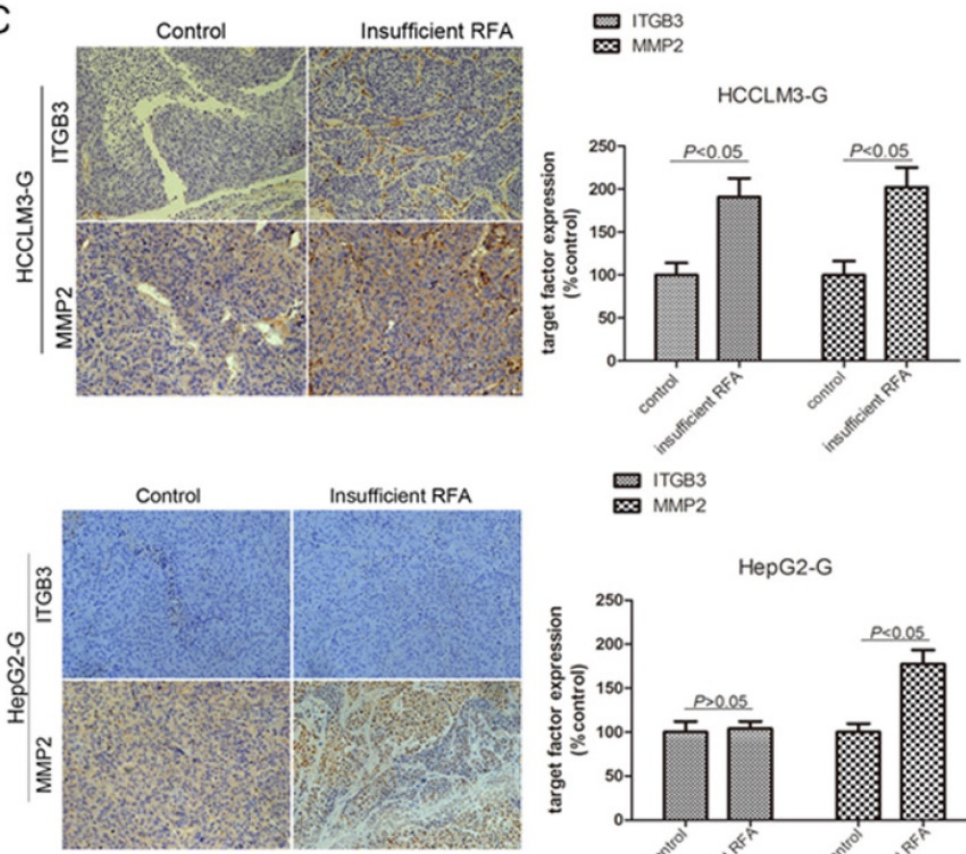

ए ITGB3 $\varpi M M P 2$

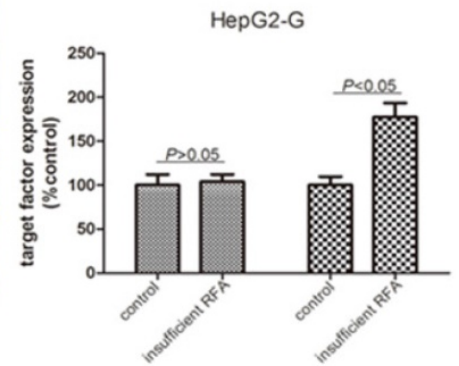

F
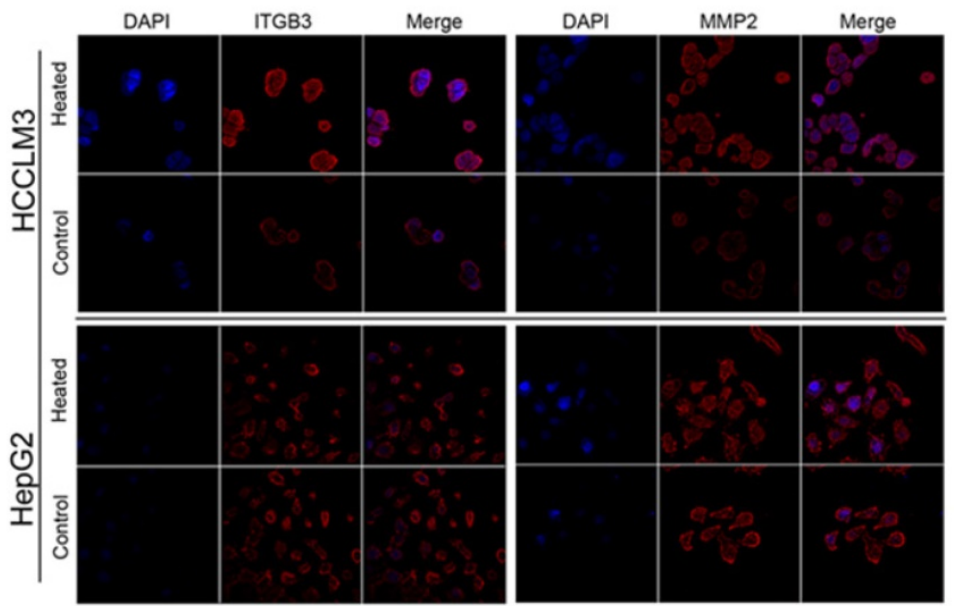

Figure 4. Insufficient RFA could up-regulated expression of the metastasis related genes Integrin $\beta 3$ (ITGB3) and MMP2 in vivo and in vitro. A Three significantly up-regulated genes (>1.5 fold) in HCCLM3 residual cancer after insufficient RFA were detected by PCR array. B Western blot analysis and (C) immunohistochemistry staining confirmed the up-regulation of ITGB3 and MMP2 in protein level in heated HCCLM3 residual cancer, and the upregulated expression of MMP2, not ITGB3 in heated HepG2 residual cancer. (D, E and F) Up-regulation of ITGB3 and MMP2 in protein and mRNA level of heated HCCLM3 cells in vitro were confirmed by western blot, immunofluorescence staining and RT-PCR, for the heated HepG2 cells, only up-regulated expression of MMP2 was detected in vitro.

\section{ITGB3 was responsible for the pro-metastatic} effects of insufficient RFA in vivo and in vitro

We tested the pro-metastatic effect of ITGB3 in xenografts tissue after insufficient RFA, the findings showed that the tumor size was significantly smaller in HCCLM3-LV-shITGB3 group compared with the HCCLM3-WT group (Fig. 6A), in addition, the lung metastasis was inhibited completely in HCCLM3-LV-shITGB3 group and no lung metastatic node was observed in H\&E staining (Fig. 6B). Western blot also demonstrated that downregulation of ITGB3 expression could weaken activation of FAK/PI3K/ AKT signaling pathway in xenografts tissue after insufficient RFA (Fig. 6C). Consistent with in vivo experiment, heat intervention also promoted 
migration and invasiveness in HCCLM3-WT cells in vitro but not in HCCLM3-LV-shITGB3 cells (Fig. 6C, D). Moreover, the HCCLM3-LV-ITGB3 (up-regulated expression of ITGB3) showed the enhanced invasive and metastatic potential even under normal culture conditions.

\section{Discussion}

Our in vivo study demonstrated that insufficient RFA could promoted invasive and metastatic potential, as indicated by increased pulmonary metastasis and IHMs and/or abdominal dissemination. To further check the biological characteristics of residual cancer, we employed a re-inoculation model. The tumor in insufficient RFA pre-treated group of HCCLM3-G showed increased pulmonary metastasis rate and tumor size, but not in HepG2-G model. Meanwhile, our findings in vitro demonstrated that the HCC cells after heat intervention exhibited increased motility and invasiveness. These observations were consistent with other researches results about biological behavior of residual cancer after insufficient RFA. In a VX2 carcinoma rabbit model, residual hepatic VX2 carcinoma after insufficient RFA could facilitate its rapid progression, and the focal tumor size and lung metastases of RFA-treated rabbits significantly increased [29]. Kroeze et al. identified that insufficient thermal ablation stimulated proliferation of residual renal carcinoma cells in a translational murine model and hypoxia, HSPs and inflammatory cells might facilitate recurrences during this process [30].
A

ITGB3

FAK

p-FAK

AKT

p-AKT

MMP2

$\beta$-actin

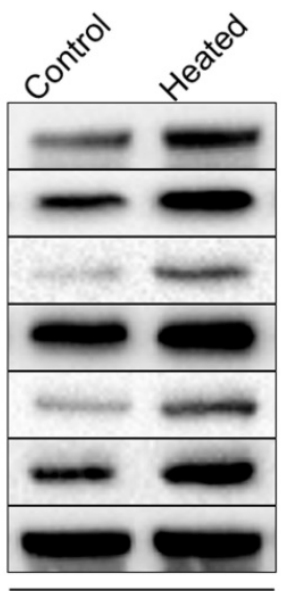

HCCLM3

B

C

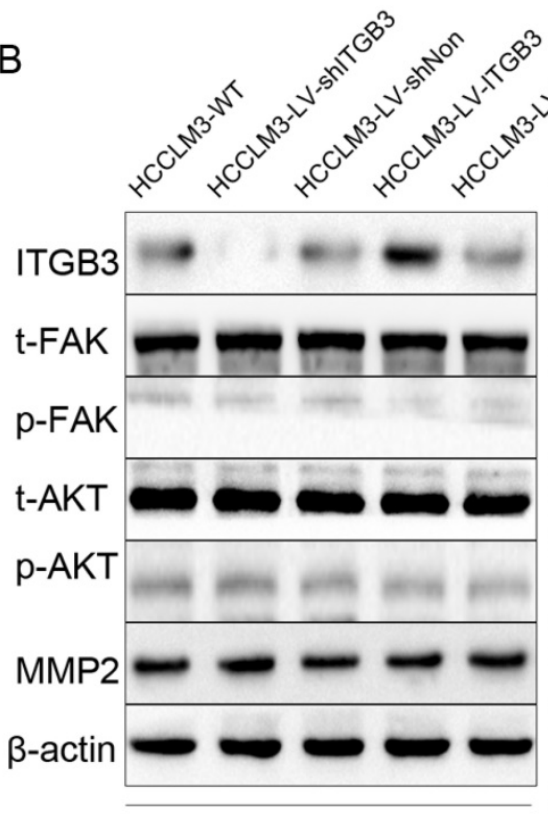

Control

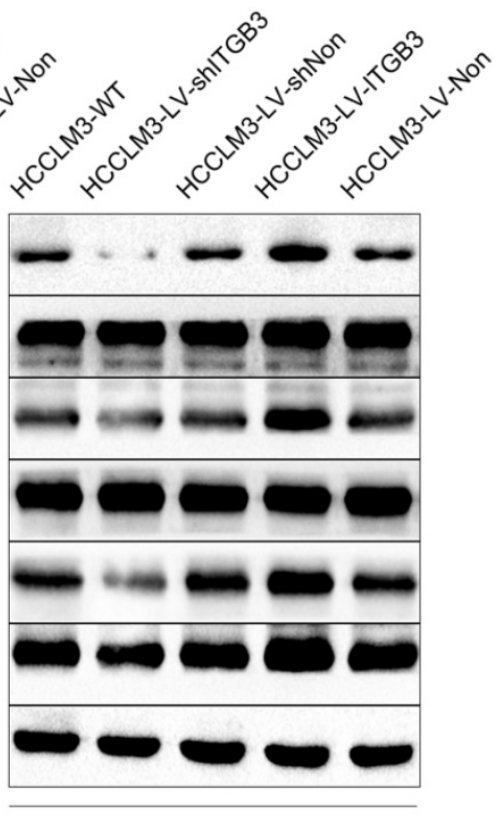

Heated

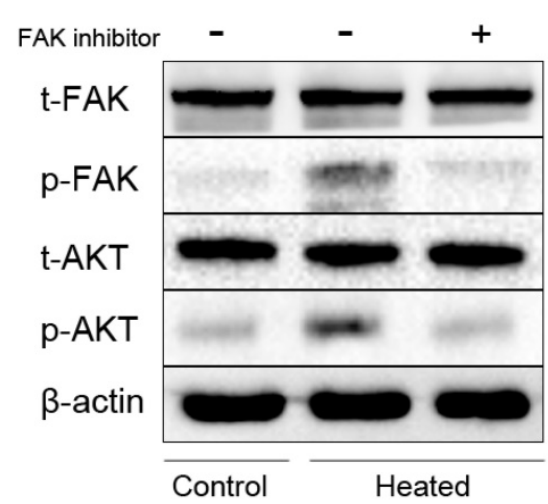

D

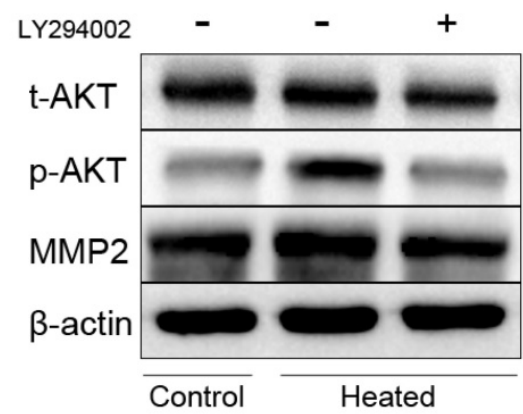

Figure 5. FAK/PI3K/AKT/MMP2 pathway was activated in HCCLM3 residual cancer after insufficient RFA and ITGB3 might play an initial role in this process. A Western blot showed the enhanced expression of ITGB3 and MMP2 of heated HCCLM3 cells accompanying with phosphorylation of FAK and AKT in vitro. B Western blot showed the effects of down-regulated expression and up-regulated expression of ITGB3 on phosphorylation level of FAK and AKT, and the expression of MMP2 in protein level in vitro. C The effects of inhibiting the expression of FAK on the expression of MMP2 and phosphorylation level of AKT in vitro were detected by western blot. D The effects of inhibiting the phosphorylation of AKT on the expression of MMP2 in vitro by western blot. 
A
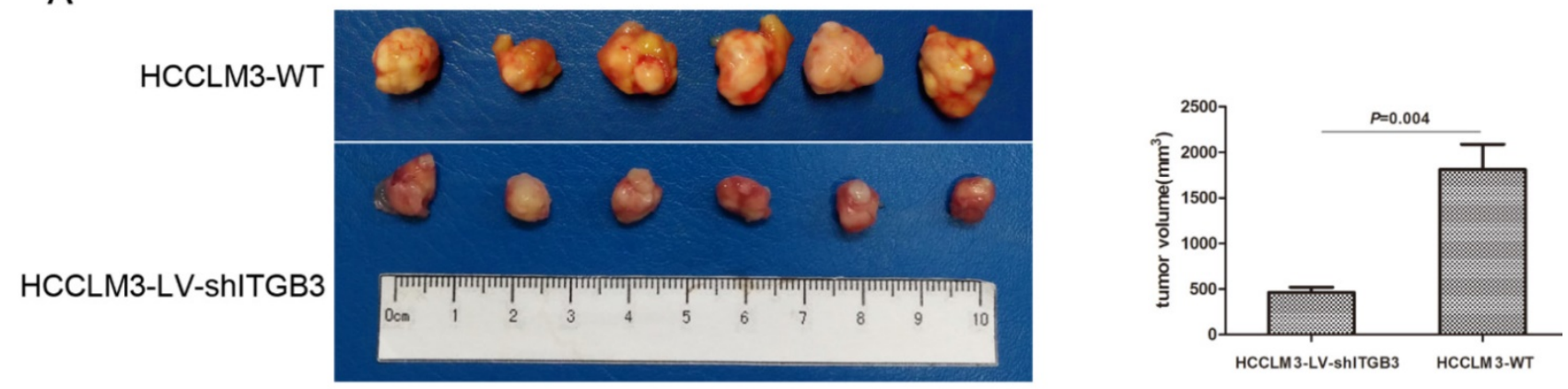

B
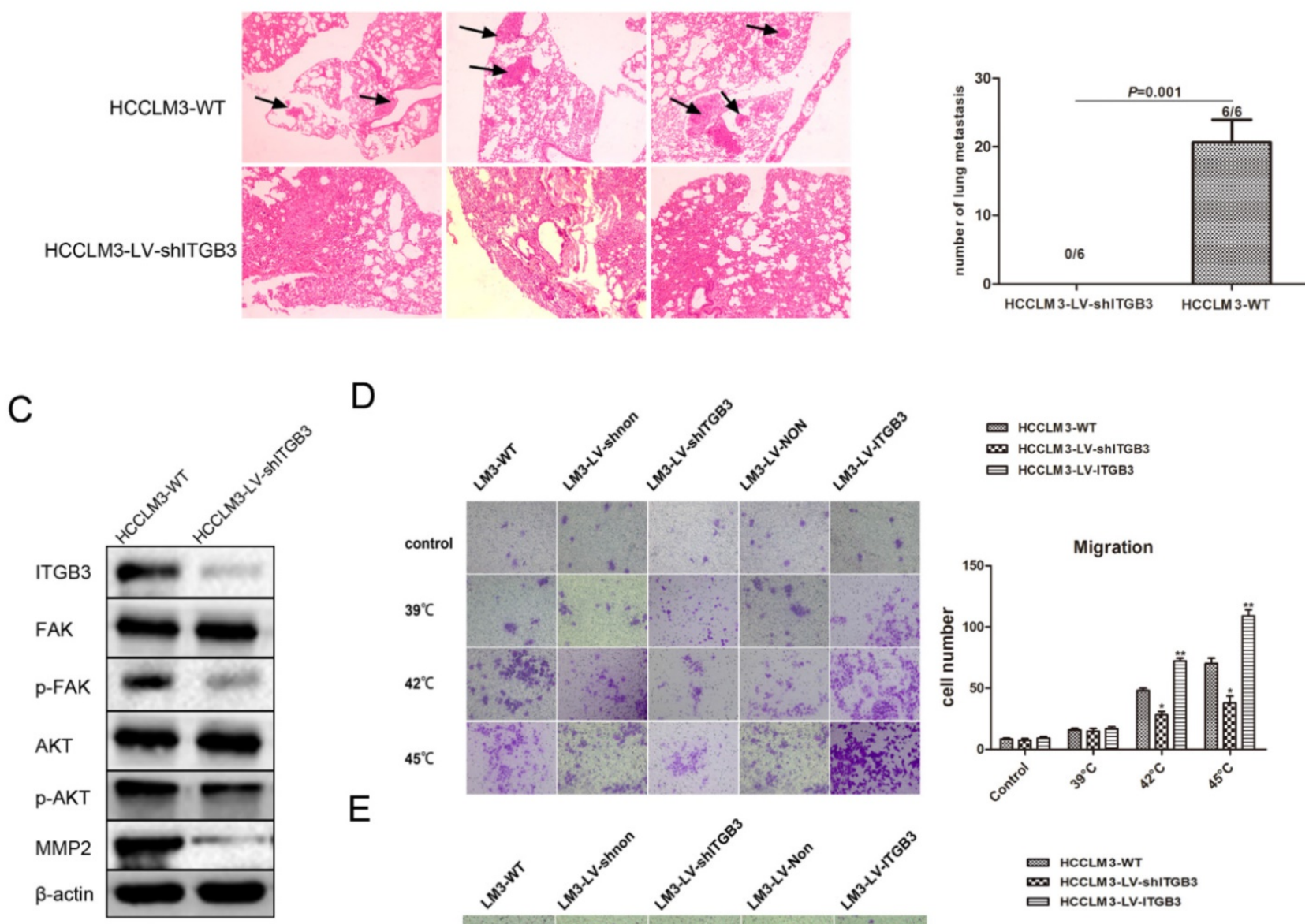

D

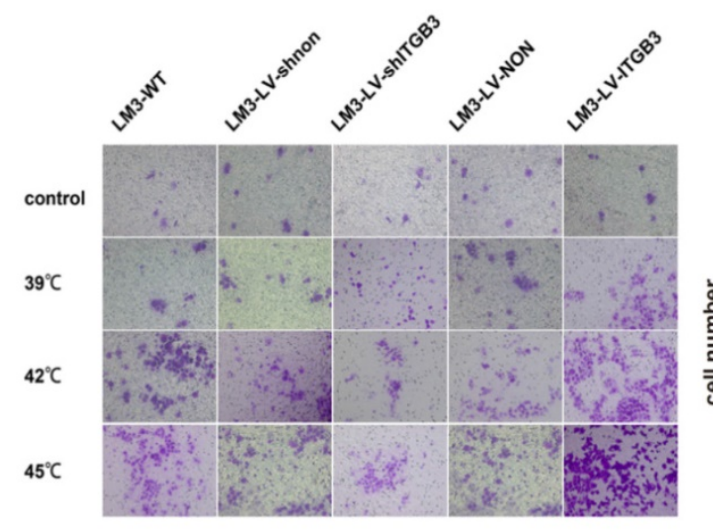

$$
\begin{aligned}
& \text { HCCLM 3-WT } \\
& \text { HCCLM 3-LV-shITGB3 } \\
& \square \text { HCCLM 3-LV-ITGB3 }
\end{aligned}
$$

E
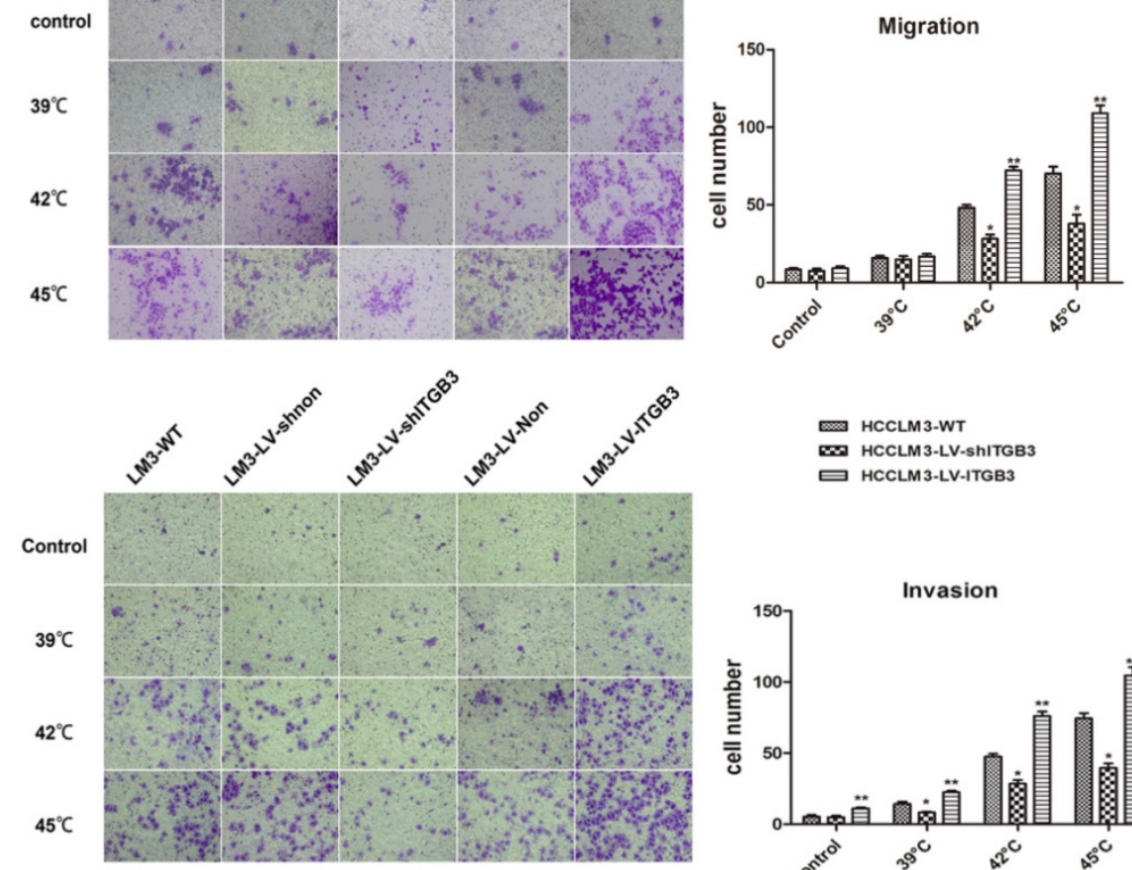

$$
\begin{aligned}
& \text { HCCLM 3-WT } \\
& \text { HCCLM 3-LV-shITGB3 } \\
& \square \text { HCCLM 3-LV-ITGB3 }
\end{aligned}
$$

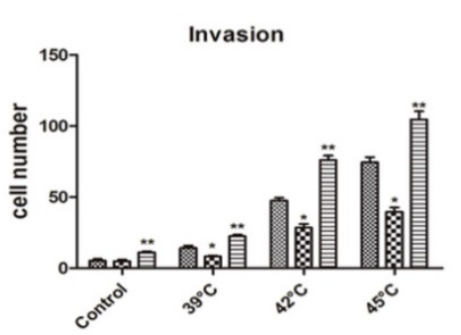

Figure 6. ITGB3 was responsible for the pro-metastatic effects of insufficient RFA in vivo and in vitro. A Tumor sizes in HCCLM3-LV-shITGB3 group were smaller than those in HCCLM3-WT group $(P=0.004)$. B Down-regulated expression of ITGB3 might inhibit the lung metastasis of HCCLM3 residual cancer after insufficient RFA ( $0 / 6$ vs $6 / 6, P=0.001)$, the right graph demonstrated the number of lung metastatic nodules in both group $(0$ vs $20.67 \pm 3.28, P=0.001)$. The black arrows represented the lung metastatic nodules. C Western blot demonstrated down-regulated expression of ITGB3 could weaken activation of FAK/PI3K/AKT signaling pathway in xenografts tissue after insufficient RFA treatment. D The effects of down-regulated expression and up-regulated expression of ITGB3 on migration ability of HCCLM3 cells were examined by transwell migration assay (HCCLM3-LV-shlTGB3 vs HCCLM3-WT, *P<0.001; HCCLM3-LV-ITGB3 vs HCCLM3-WT, **P<0.005). E The effects of down-regulated expression and up-regulated expression of ITGB3 on invasion ability of HCCLM3 cells were examined by transwell invasion assay (HCCLM3-LV-shITGB3 vs HCCLM3-WT, *P<0.05; HCCLM3-LV-ITGB3 vs HCCLM3-WT, **P<0.005). 
To further verify the underlying molecular mechanism of the above phenomenon, the PCR array was used to seek for the tumor metastasis-related genes which had significantly different expression between the insufficient RFA group and the control. Our findings presented ITGB3 and Matrix metalloproteinase-2 (MMP2) were the two main changed genes which were also identified by western blot analysis. Meanwhile, our in vitro findings indicated that the expression of ITGB3 and MMP2 were significantly up-regulated in HCCLM3 cells after heat intervene.

Matrix metalloproteinases (MMPs), a family of zinc dependent endopeptidases, comprise a highly regulated family of structurally-related enzymes capable of degrading most, if not all, of the components of the extracellular matrix [31, 32], and play vital roles in the degradation of basement membranes and extracellular matrix that are crucial for the invasion and motility of many types of cells [33-35]. Several MMPs are believed to be important in the process of tumor metastasis, especially MMP-2 and MMP-9. Both two MMPs preferentially degrade basement membrane components such as type-IV collagen, unmask cryptic biologically relevant sites in ECM components. MMP2 is a $72-\mathrm{kDa}$ type IV collagenase, and play a pivotal role in rapid tumor cellular proliferation, increased motility, invasion and angiogenesis by itself or via activating other key molecules [36, 37]. Several studies had also revealed the interaction of MMPs and integrin in relation to tumor progression. Chetty et al. found that MMP2 altered VEGF expression via aV $\beta 3$ integrin-mediated PI3K/AKT signaling in A549 lung cancer cells, and suppression of MMP2 with MMP2 specific inhibitor decreased integrin- $\alpha \mathrm{V} \beta 3$-mediated induction of PI3K/AKT leading to declined tumor angiogenesis and metastasis [38]. In addition, another study revealed that $\beta 6$ induced phosphorylation of ETS1 via the ERK/MAPK pathways, through which the MMP-3/MMP-9 promoters were stimulated, thereby leading to the up-regulation of MMP-3/MMP-9, and subsequent the invasion of colon cancer cells [39]. On the basis of the previous results, we hypothesized that insufficient RFA could lead to up-regulated ITGB3 expression, and then the overexpression of ITGB3 might promote the invasiveness of residual cancer by enhanced expression of MMP2 via somehow signaling pathway.

To explore the possible signaling pathway by which ITGB3 regulated the activity of MMP2, we paid our attention to focal adhesion kinase (FAK), which was an intracellular nonreceptor tyrosine kinase and an important modulator of integrin dependent focal cell contacts, thereby orchestrating well known integrin-initiated outside-in signaling events. FAK colocalizes with $\beta$ integrin, becomes activated by autophosphorylation at position tyrosine 397, then performs downstream signaling events, and plays critical roles in cell motility [40]. In in vitro, our study demonstrated that the up-regulation of $\beta 3$ integrin in heat-treated HCCLM3 cells was accompanied by enhancement of FAK phosphorylation. Activation of FAK induces the activation of several downstream signaling pathways, including the PI3K/AKT, MAPK, and Src-mediated pathways [41-43]. In present study, our data showed that heat intervention induced the phosphorylation of FAK accompanied with phosphorylation of AKT in vitro. The phosphoinositide 3-kinase (PI3K) / AKT pathway is a key signal transduction system that links oncogenes and multiple receptor classes to many essential cellular functions, and is perhaps the most commonly activated signaling pathway in human cancer. It plays a key role in inhibiting the apoptotic cells and promoting the proliferation, and it is closely associated with a variety of human tumor developments [44].

A number of studies had identified the significant effect of PI3K/AKT pathway in proliferation and invasion of HCC. Wang et al. suggested that $\mathrm{HBV} \times(\mathrm{HBx})$ gene, one of the four genes in the HBV genome, could promote liver progenitor cells proliferation by up-regulation of cyclin-D1 via activation PI3K/AKT pathways [45]. Cao et al. used clinical samples to show that PI3K/AKT signaling pathway played an important role in proline-rich tyrosine kinase 2 (Pyk2) Pyk2-mediated VEGF expression during HCC progression and invasion [46]. Based on the above findings, given that insufficient RFA might enhance invasiveness and metastasis of residual cancer via FAK/PI3K/AKT/MMP2 signaling pathway and ITGB3 was the vital promoter of this pathway.

The results that in vitro and in vivo had further demonstrated that the up-regulation of ITGB3 was positively correlated with insufficient RFA-induced invasion and metastasis. In addition, blocking of ITGB3 by shITGB3 transfection almost completely abrogated the enhanced aggressiveness of heat-treated HCCLM3 cells in vitro and residual cancer after insufficient RFA in vivo. These findings indicated a contributory role of ITGB3 in insufficient RFA induced metastatic potential.

Our study revealed that insufficient RFA promoted the invasiveness and metastasis of HCCLM3-derived residual cancer via ITGB3/FAK/ PI3K/AKT/MMP2 signaling pathway. The following evidences support this conclusion. First, insufficient RFA enhanced metastasis potential of residual cancer 
accompanied with up-regulation of ITGB3, moreover, a positive relationship between up-regulation of ITGB3 and phosphorylation of FAK and AKT was found in heat-treated HCCLM3 cells in vitro and in residual cancer, and then the activation of PI3K/AKT signaling induced the up-regulated expression of MMP2. Second, knockdown of ITGB3 by shRNA not only resulted in the partial or complete repression of phosphorylation of FAK and AKT, but also decreased the expression of MMP2. HCCLM3 and HepG2 are two types of human HCC cell lines with different biological characteristics. HCCLM3 cell has the potential for lung or distant metastasis, however, HepG2 cell without the potential for lung metastasis. In the present study, the expression of ITGB3 did not change with the incubation temperature increasing, but the expression of MMP2 was significantly enhanced might through other pathways, and need further investigation.

In conclusion, our findings were insufficient RFA could inhibit the growth of HCC xenografts, however, induced enhanced metastasis abilities of HCC cells in vivo and in vitro, which was mediated by FAK/PI3K/AKT/MMP2 signaling pathway, and the up-regulated expression of ITGB3 induced by insufficient RFA might be the promoter of this signaling pathway. Therefore, further studies will be conducted to how to decrease the invasiveness and metastasis of residual cancer and improve the curative effects of RFA in patients of HCC.

\section{Acknowledgements}

This project was supported by the National Natural Science Foundation of China (NO. 81372314 and 81372655), National S\&T Major Project for Infectious Diseases of China (NO.2012ZX10002-017), National Key Project for Infectious Diseases (NO.2012ZX10002012-004).

\section{Competing Interests}

The authors have declared that no competing interest exists.

\section{References}

1. Jemal A, Bray F, Center MM, et al. Global cancer statistics. CA Cancer J Clin. 2011; 61:69-90

2. Lau WY, Lai EC, et al. The current role of radiofrequency ablation in the management of hepatocellular carcinoma: a systematic review. Ann Surg. 2009; 249:20-25.

3. Lee DH, Lee JM, Lee JY et al. Radiofrequency ablation of hepatocellular carcinoma as first-line treatment: long-term results and prognostic factors in 162 patients with cirrhosis. Radiology. 2014; 270:900-909.

4. Bruix J, Gores GJ, Mazzaferro V, et al. Hepatocellular carcinoma: clinical frontiers and perspectives. Gut. 2014; 63:844-855.

5. Lam VW, Ng KK, Chok KS, et al. Risk factors and prognostic factors of local recurrence after radiofrequency ablation of hepatocellular carcinoma. J Am Coll Surg 2008; 207:20-29.

6. Shiina S, Tateishi R, Arano $\mathrm{T}$, et al. Radiofrequency ablation for hepatocellular carcinoma: 10-year outcome and prognostic factors. Am J Gastroenterol 2012; 107:569-577
7. Kim YS, Lim HK, Rhim $\mathrm{H}$, et al. Ten-year outcomes of percutaneous radiofrequency ablation as first-line therapy of early hepatocellular carcinoma: analysis of prognostic factors. J Hepatol. 2013; 58:89-97.

8. Tajima $\mathrm{H}$, Ohta $\mathrm{T}$, Okamoto $\mathrm{K}$, et al. Radiofrequency ablation induces dedifferentiation of hepatocellular carcinoma. Oncol Lett. 2010; 1:91-94.

9. Nicoli N, Casaril A, Abu Hilal M, et al. A case of rapid intrahepatic dissemination of hepatocellular carcinoma after radiofrequency thermal ablation. Am J Surg. 2004; 188:165-167.

10. Makrilia N, Kollias A, Manolopoulos L, et al. Cell adhesion molecules: role and clinical significance in cancer. Cancer Invest 2009; 27: 1023-1037.

11. Weis SM, Cheresh DA. $\alpha$ v integrins in angiogenesis and cancer. Cold Spring Harb Perspect Med. 2011; 1:a006478.

12. Giancotti FG, Tarone G. Positional control of cell fate through joint integrin/receptor protein kinase signaling. Annu Rev Cell Dev Biol. 2003; 19:173-206.

13. Calderwood DA, Campbell ID, Critchley DR. Talins and kindlins: partners in integrin-mediated adhesion. Nat Rev Mol Cell Biol. 2013; 14:503-517.

14. Kuphal S, Bauer R, Bosserhoff AK. Integrin signaling in malignant melanoma. Cancer Metastasis Rev. 2005; 24:195-222

15. Luo BH, Carman CV, Springer TA. Structural basis of integrin regulation and signaling. Annu Rev Immunol. 2007; 25: 619-647.

16. Sims TN, Dustin ML. The immunological synapse: integrins take the stage. Immunological Reviews. 2002; 186: 100-117.

17. Weiss LA, Kosova G, Delahanty RJ, et al. Variation in ITGB3 is associated with whole-blood serotonin level and autism susceptibility. Eur J Hum Genet. 2006; 14: 923-931.

18. Sheldrake HM, Patterson LH. Function and antagonism of beta3 integrins in the development of cancer therapy. Curr Cancer Drug Targets. 2009; 9:519-540.

19. Felding-Habermann B, O'Toole TE, Smith JW, et al. Integrin activation controls metastasis in human breast cancer. Proc Natl Acad Sci USA. 2001; 98; 1853-1858.

20. McCabe NP, De S, Vasanji A, et al. Prostate cancer specific integrin $\alpha V \beta 3$ modulates bone metastatic growth and tissue remodeling. Oncogene. 2007; 26: 6238-6243.

21. Felding-Habermann B, Fransvea E, O'Toole TE, et al. Involvement of tumor cell integrin av $\beta 3$ in hematogenous metastasis of human melanoma cells. Clin Exp Metastasis. 2002; 19: 427-436.

22. Yang BW, Liang $\mathrm{Y}, \mathrm{Xia} \mathrm{JL}$, et al. Biological characteristics of fluorescent protein-expressing human hepatocellular carcinoma xenograft model in nude mice. Eur J Gastroenterol Hepatol. 2008; 20: 1077-1084.

23. Tian J, Tang ZY, Ye SL, et al. New human hepatocellular carcinoma (HCC) cell line with highly metastatic potential (MHCC97) and its expressions of the factors associated with metastasis. Br J Cancer. 1999; 81: 814-821.

24. Wang L, Tang ZY, Qin LX, et al. High-dose and long-term therapy with interferon-alfa inhibits tumor growth and recurrence in nude mice bearing human hepatocellular carcinoma xenografts with high metastatic potential. Hepatology. 2000; 32: 43-48.

25. Zhang W, Zhu XD, Sun HC, et al. Depletion of tumor-associated macrophages enhances the effect of sorafenib in metastatic liver cancer models by antimetastatic and antiangiogenic effects. Clin Cancer Res. 2010; 16:3420-3430.

26. Liu L, Ren ZG, Shen Y, et al. Influence of hepatic artery occlusion on tumor growth and metastatic potential in a human orthotopic hepatoma nude mouse model: relevance of epithelial-mesenchymal transition. Cancer Sci. 2010; 101:120-128.

27. Lu L, Sun HC, Zhang W, et al. Aspirin minimized the pro-metastasis effect of sorafenib and improved survival by up-regulating HTATIP2 in hepatocellular carcinoma. PLoS One. 2013; 31:e65023.

28. Siesser PM, Hanks SK. The signaling and biological implications of FAK overexpression in cancer. Clin Cancer Res. 2006 $12 \cdot 3233-3237$.

29. Ke S, Ding XM, Kong J, et al. Low temperature of radiofrequency ablation at the target sites can facilitate rapid progression of residual hepatic VX2 carcinoma. J Transl Med. 2010; 8:73.

30. Kroeze SG, van Melick HH, Nijkamp MW, et al. Incomplete thermal ablation stimulates proliferation of residual renal carcinoma cells in a translational murine model. BJU Int. 2012; 110: E281-286.

31. Laughner $\mathrm{E}$, Taghavi $\mathrm{P}$, Chiles $\mathrm{K}$, et al. HER2 (neu) signaling increases the rate of hypoxia-inducible factor 1alpha (HIF-1alpha) synthesis: novel mechanism for HIF-1-mediated vascular endothelial growth factor expression. Mol Cell Biol. 2001: 21:3995-4004.

32 Trisciuoglio D, Iervolino A, Zupi G, et al. Involvement of PI3K and MAPK signaling in bcl-2-induced vascular endothelial growth factor expression in melanoma cells. Mol Biol Cell. 2005; 16:4153-4162.

33. Visse R, Nagase H. Matrix metalloproteinases and tissue inhibitors of metalloproteinases: structure, function, and biochemistry. Circ Res. 2003; 92:827-839.

34. Choo EJ, Rhee $\mathrm{YH}$, Jeong SJ, et al. Anethole exerts antimetatstaic activity via inhibition of matrix metalloproteinase $2 / 9$ and AKT/mitogen-activated kinase/nuclear factor kappa B signaling pathways. Biol Pharm Bull. 2011; $34: 41-46$

35. Chen NH, Liu JW, Zhong JJ. Ganoderic acid Me inhibits tumor invasion through down-regulating matrix metalloproteinases $2 / 9$ gene expression. J Pharm Sci. 2008; 108:212-216.

36. Chetty C, Lakka SS, Bhoopathi $\mathrm{P}$, et al. Tissue inhibitor of metalloproteinase 3 suppresses tumor angiogenesis in matrix metalloproteinase 2-down-regulated lung cancer. Cancer Res. 2008; 68: 4736-4745. 
37. Badiga AV, Chetty C, Kesanakurti D, et al. MMP-2 siRNA inhibits radiation-enhanced invasiveness in glioma cells. PLoS One. 2011; 6: e20614.

38. Chetty C, Lakka SS, Bhoopathi P, et al. MMP-2 alters VEGF expression via alphaVbeta3 integrin-mediated PI3K/AKT signaling in A549 lung cancer cells. Int J Cancer. 2010; 127: 1081-1095.

39. Gao H, Peng C, Liang B, et al. $\beta 6$ integrin induces the expression of metalloproteinase-3 and metalloproteinase-9in colon cancer cells via ERK-ETS1 pathway. Cancer Lett. 2014; 354: 427-437.

40. Lin $\mathrm{Y}$, Rao J, Zha XL, et al. Angiopoietin-like 3 induces podocyte F-actin rearrangement through integrin $\alpha(\mathrm{V}) \beta_{3} / \mathrm{FAK} / \mathrm{PI} 3 \mathrm{~K}$ pathway-mediated Rac1 activation. Biomed Res Int. 2013; 2013:135608.

41. Sonoda $Y$, Watanabe $S$, Matsumoto $Y$, et al. FAK is the upstream signal protein of the phosphatidylinositol 3-kinase-Akt survival pathway in hydrogen peroxide-induced apoptosis of a human glioblastoma cell line. J Biol Chem. 1999; 274:10566-10570

42. Wang JG, Miyazu M, Xiang P, et al. Stretch-induced cell proliferation is mediated by FAK-MAPK pathway. Life Sci. 2005; 76:2817-2825.

43. Thamilselvan V, Craig DH, Basson MD. FAK association with multiple signal proteins mediates pressure-induced colon cancer cell adhesion via a Src-dependent PI3K/Akt pathway. FASEB J. 2007; 21:1730-1741.

44. Liu P, Cheng H, Roberts TM, et al. Targeting the phosphoinositide 3-kinase pathway in cancer. Nat Rev Drug Discov. 2009; 8:627-644.

45. Wang HY, Yang SL, Liang HF, et al. HBx protein promotes oval cell proliferation by up-regulation of cyclin D1 via activation of the MEK/ERK and PI3K/ Akt pathways. Int J Mol Sci. 2014; 15:3507-3518.

46. Cao J, Chen Y, Fu J, et al, Wang HY. High expression of proline-rich tyrosine kinase 2 is associated with poor survival of hepatocellular carcinoma via regulating phosphatidylinositol 3-kinase/AKT pathway. Ann Surg Oncol. 2013; 20: S312-23. 